\title{
Editorial
}

\section{A luta dos profissionais de saúde no enfrentamento da COVID-19}

$\mathrm{O}$ Brasil está passando pela mais grave pandemia de uma doença infecciosa causada por um novo coronavírus (SARS-CoV-2). A doença chamada COVID-19 é potencialmente fatal e representa o mais importante problema mundial de saúde pública dos últimos 100 anos, comparado apenas com a gripe espanhola que matou cerca de 25 milhóes de pessoas entre 1918 e 1920. A pandemia pelo SARS-CoV-2 teve início na cidade de Wuhan, região central da China, relacionada a transmissão em um mercado de frutos do mar e de animais vivos. ${ }^{(1)}$ Rapidamente se disseminou para toda China, a Ásia e, em dois meses, atingiu todos os continentes.

SARS-CoV-2 é altamente transmissível por gotículas e contato, principalmente em locais fechados e ambientes hospitalares. Um indivíduo com infecção pelo novo coronavírus transmite para outras duas ou três pessoas, dependendo das condiçóes ambientais. Locais fechados com pouca ventilação e baixa luminosidade facilitam a transmissão do vírus. Esta taxa de transmissão é chamada número reprodutivo, que na COVID-19 varia entre 2,0 e 3,5. O controle da epidemia acontece quando o número reprodutivo da COVID-19 é reduzido a menos de um, fazendo com que a quantidade de casos diminua lentamente. Acredita-se poderíamos suprimir a circulação de vírus em um grau considerável quando atingíssemos o número reprodutivo para menos de 0,2. O vírus pode permanecer no ambiente por horas a dias dependendo da superfície e das condiçóes ambientais. O novo coronavírus é inativado com facilidade com germicidas utilizados no ambiente hospitalar, incluindo o álcool à $70 \%$ e o hipoclorito de sódio. A higiene ambiental é fundamental especialmente no ambiente hospitalar.

Um fator importante na transmissibilidade do COVID-19 é a alta carga viral no trato respiratório superior, mesmo entre pacientes pré-sintomáticos, que o distingue de outras doenças respiratórias. Em muitos indivíduos, particularmente idosos, o diagnóstico da infecção baseada em sintomas é mais difícil: muitos não apresentam febre, têm tosse crônica por outras patologias ou apresentam dispneia aos esforços por insuficiência cardíaca prévia. Em um surto em casa de repouso nos Estados Unidos da América, a triagem isoladamente baseada em sintomas clínicos não conseguiu diagnosticar muitos idosos com infecção e não foi suficiente para controlar a transmissão da COVID-19. ${ }^{(2)}$

Os profissionais de saúde são particularmente susceptíveis a infecção. No Brasil, bem como em outros países, milhares de profissionais de saúde foram afastados das atividades profissionais por terem adquirido a infecção 
e muitos morreram em consequência da COVID-19. ${ }^{(3,4)} \mathrm{Na}$ Itália, 20\% dos profissionais de saúde que estavam trabalhando na linha de frente do atendimento a COVID-19 tiveram a infecção e muitos morreram. ${ }^{(3)}$

Os dados das equipes de profissionais de saúde na linha de frente de atendimento de casos de COVID-19 mostram exaustão física e mental, dificuldades na tomada de decisão e ansiedade pela dor de perder pacientes e colegas, além do risco de infecção e a possibilidade de transmitir para familiares. ${ }^{(3)}$ Assim, garantir assistência médica para os profissionais de saúde e apoio psicológico são fundamentais. Da mesma forma, realizar testes diagnósticos nos sintomáticos com rapidez.

A reação em cadeia de polimerase em tempo real (RT-PCR) está indicada nos profissionais de saúde sintomáticos, sendo o melhor momento de coleta da secreção oro ou nasofaringe entre o terceiro e sétimo dia do início dos sintomas. Em alguns indivíduos, o RT-PCR pode permanecer detectável por longos períodos, até 2 a 6 semanas, porém na maior parte das vezes, representam material genético inativo, sem importância na transmissão. Os testes sorológicos são capazes de detectar os níveis de anticorpos IgM, IgA e IgG, por diversas técnicas como imunoensaio automatizado em metodologia de quimioluminescência, imunoenzimático, além do teste de imunocromatografia (teste rápido - menor sensibilidade). Em geral, apresentam sensibilidade ao entre 60 e $70 \%$ em torno do 7 o dia e ao redor de $90 \%$ após o $10^{\circ}$ dia. A presença de $\operatorname{IgM}$ ou $\operatorname{IgA}$ indicam infecção aguda e IgG positivo indica contato prévio com o SARS-CoV-2 e pode estar relacionado a imunidade contra o vírus. Não sabemos se a infecção confere imunidade neutralizante e duradoura. Assim, mesmo profissionais de saúde com IgG positivo devem utilizar os EPIs quando em contato com pacientes suspeitos ou confirmados de COVID-19.

Os profissionais de saúde que cuidam de seus pais idosos ou filhos pequenos são diretamente afetados pelo fechamento das escolas e políticas de distanciamento social. Entretanto, sem vacina ou tratamento específico contra o SARS-CoV-2, o isolamento residencial, o distanciamento social e o uso de máscaras de forma universal associado as medidas de higiene podem retardar a transmissão do vírus e diminuir o número de pessoas que procuram os hospitais ao mesmo tempo, adequando o sistema único de saúde a demanda dos casos graves, evitando um colapso de toda rede pública de assistência hospitalar.

À medida que a epidemia acelera no Brasil, o acesso a equipamentos de proteção individual (EPI) para profissionais de saúde é uma preocupação constante. A escassez de EPIs está sendo observada em diversas instituições brasileiras como em muitos países. ${ }^{(5)}$ A manutenção de EPIs nas instituições de saúde deve ser uma política de Estado, os governos devem se mobilizar para que a indústria nacional responda a este desafio. Infelizmente, não é isto que estamos vendo, os preços dos EPIs, especialmente máscaras e aventais descartáveis, tiveram importantes aumentos, associado ao desabastecimento do mercado. Temos uma enorme dependência da indústria da China que produz grande parte dos EPIs utilizados no Brasil. 
A readequação dos hospitais para o enfrentamento da epidemia de COVID-19 tem sua maior dificuldade na contratação de profissionais qualificados. Não é fácil encontrar rapidamente profissionais capazes de dar atendimento com qualidade e segurança a pacientes com COVID-19, especialmente nas unidades de terapia intensiva. A doença pelo SARS-CoV-2 vai muito além da insuficiência respiratória que leva o paciente ao hospital. $\mathrm{Na}$ infecção grave, existe uma importante liberação de citocinas, principalmente IL-6, com intensa resposta inflamatória, determinando choque séptico e fenômenos tromboembólicos relacionados a coagulação intravascular disseminada. ${ }^{(1)}$ Alguns pacientes necessitam de hemodiálise e evoluem com complicaçôes cardiológicas que requerem profissionais experientes para identificar, tomar decisão e tratar as complicaçôes.

A COVID-19 também mostra a face da desigualdade social no Brasil. A epidemia que se iniciou nos bairros de alto nível socio econômico está disseminando-se rapidamente para a periferia dos grandes centros urbanos, a exemplo da capital paulista, com elevado número de óbitos. ${ }^{(4)}$ Não podemos esquecer que a maior parte da força de trabalho dos hospitais mora na periferia das cidades e certamente teremos uma nova onda de infecção, com enorme impacto no afastamento de profissionais nos hospitais.

Nenhum país está preparado para enfrentar uma epidemia de COVID-19, que determina importantes impactos negativos na economia, na assistência médica e na saúde mental da sociedade como um todo. Os grandes desafios para os hospitais são de reorganizar o atendimento, ampliar leitos de unidade de terapia intensiva, abastecer com equipamentos de proteçấo individual e ter profissionais capacitados. $\mathrm{O}$ fomento à pesquisa é fundamental para entendermos melhor a doença, consigamos medicamentos eficientes, bem como a vacina. Até lá, para nós como profissionais de saúde, é importante seguirmos as recomendaçóes e protocolos institucionais, fortalecer a comunicaçáo, a empatia, nos manter atualizados e saudáveis para enfrentar este importante desafio histórico.

\section{Agradecimentos}

Ao Conselho Nacional de Desenvolvimento Científico e Tecnológico CNPq (Processo no 307784/2018-5).

Prof. Dr. Eduardo Alexandrino Servolo Medeiros (https://orcid.org/0000-0002-6205-259X)

Prof. Associado da Disciplina de Infectologia e Presidente da Comissäo de Controle de Infecção Hospitalar e Programa de Antimicrobial Stewardship do Hospital São Paulo, Escola Paulista de Medicina - Unifesp. Pesquisador do Conselho Nacional de Desenvolvimento Cientifico e Tecnológico-CNPq. 
Como citar:

Medeiros EA. A luta dos profissionais de saúde no enfrentamento da COVID-19. Acta

Paul Enferm. 2020;33:e-EDT20200003

DOI:http://dx.doi.org/10.37689/acta-ape/2020EDT0003

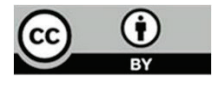

\section{Referências}

1. Rothan HA, Byrareddy SN. The epidemiology and pathogenesis of coronavirus disease (COVID-19) outbreak. J Autoimmun. 2020;109:102433.

2. Arons MM, Hatfield KM, Reddy SC et al. Presymptomatic SARS-CoV-2 infections and transmission in a skilled nursing facility. N Engl J Med, April 24, 2020. [cited 2020 Apr 27]. Available from: DOl: https://doi. org/10.1056/NEJMoa2008457.

3. The Lancet. COVID-19: protecting health-care workers. Lancet. 2020;395(10228):922.

4. Boletim Diário Covid-19 no município de São Paulo de 23 de abril de 2020 [Internet]. [citado 2020 Abrn27]. Disponível em https://www.prefeitura.sp.gov.br/cidade/secretarias/saude/vigilancia_em_saude/ doencas_e_agravos/coronavirus/index.php?p=295572. Acessado em 26/04/2020.

5. Ferioli M, Cisternino C, Leo V, Pisani L, Palange P, Nava S. Protecting healthcare workers from SARS-CoV-2 infection: practical indications. Eur Respir Rev. 2020;29(155):200068. 